\title{
DETECTING CENTER PIVOTS IN MATOPIBA USING HOUGH TRANSFORM AND WEB TIME SERIES SERVICE
}

\author{
M. L. Rodrigues ${ }^{1, *}$, T. S. Körting ${ }^{2}$, G. R. de Queiroz $^{2}$, C. P. Sales ${ }^{1}$, L. A. R. da Silva ${ }^{1}$ \\ ${ }^{1}$ Graduate program in Applied computing, National Institute for Space Research, São José dos Campos, SP, \\ Brazil - (marcos.rodrigues, camila.sales, leoni.silva)@inpe.br \\ ${ }^{2}$ Image Processing Division (DPI), National Institute for Space Research, São José dos Campos, SP, \\ Brazil - (thales.korting,gilberto.queiroz)@inpe.br
}

KEY WORDS: Center pivots, Hough Transform, Landsat, MODIS, Time series

\begin{abstract}
:
In the last decades, the Brazilian Cerrado biome has undergone major transformations due to the expansion of the agricultural frontier. The region called MATOPIBA acronym for states Maranhão, Tocantins, Piauí, and Bahia can be considered very attractive for agricultural expansion. The Cerrado predominates in the MATOPIBA region (91\% of the area), also having small areas of the Amazon and Caatinga biomes to the northeast and east, respectively. In this work, we will present a study to identify center pivot irrigation systems in the MATOPIBA region using remote sensing images from Landsat- 8 satellite. The methodology is based on the use of robust edge detection techniques such as Canny, Circular Hough Transform (CHT) and time series extraction through the Moderate Resolution Imaging Spectroradiometer (MODIS) product MOD13Q1 which has two vegetation indices NDVI and EVI. These time series will be used to filter the detected circles, seeking to eliminate the circles that do not correspond to center pivots. Our approach detected $80 \%$ of the center pivots mapped by the Brazilian National Water Agency (ANA) used as a knowledge base. The states with better detection were Piauí and Bahia that showed the accuracy of $90 \%$ and $85 \%$ respectively, Maranhão obtained $57 \%$ and Tocantins $41 \%$.
\end{abstract}

\section{INTRODUCTION}

Brazil is currently expanding its agricultural activity towards the Cerrado. There is an indication that the expansion in this area occurred mainly due to the Soy Moratorium in the Amazon Biome (MAPA, 2017). It is important to mention that agricultural expansion in this area impacts mainly native vegetation, but also water resources are under pressure, especially in highly mechanized crops.

Irrigation is an agricultural practice that employs a set of equipment and techniques to address the total or partial deficiency of water for cultivation. However, the use of water by irrigation alters the conditions of availability for other applications in its area of action, since the water withdrawn is consumed by the evapotranspiration of plants and soil, not returning directly to water bodies. Moreover, irrigation activity in Brazil is responsible for the largest volume withdrawal $\left(969 \mathrm{~m}^{3} / \mathrm{s}\right)$ and consumption $\left(745 \mathrm{~m}^{3} / \mathrm{s}\right)$, this means about $46 \%$ of total water withdrawal $\left(2105 \mathrm{~m}^{3} / \mathrm{s}\right)$ and $67 \%$ of total water consumption $\left(1110 \mathrm{~m}^{3} / \mathrm{s}\right.$ ) (Figure 1) ANA, 2017).

The identification of irrigated areas and crop types is necessary for a number of reasons, such as pollution, water resource management, charge for use of the water, estimation of production, land cover, land use, deforestation, and so on. However, in most cases, the information available in this regard comes from the registers on the system of water resources registration, generally supplied by the user of water or from inspection carried out by regulatory water agencies. These data commonly present inconsistencies due to lack of updates or omissions on the part of producers (Bastiaanssen et al., 2000). Therefore, alternative strategies must be developed to acquire this information. In this

\footnotetext{
*Corresponding author
}

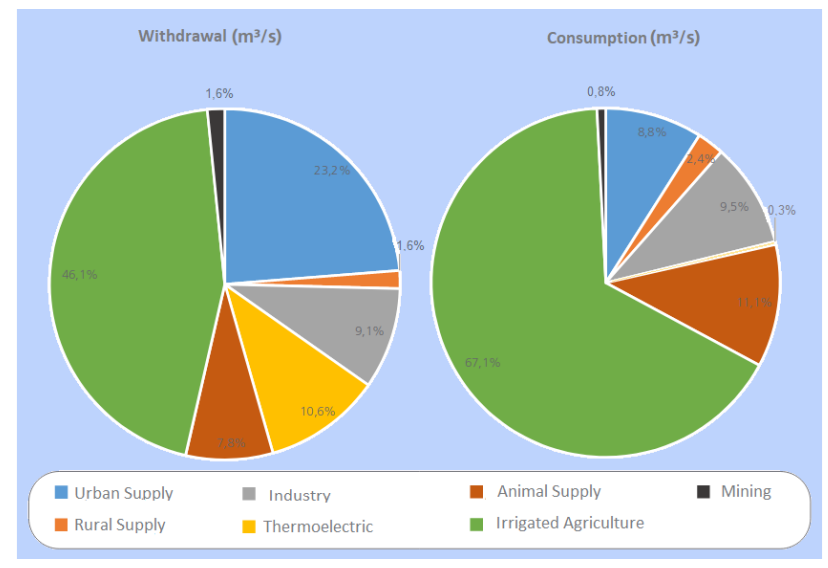

Figure 1. Water use in Brazil by sectors. Source: Adapted from ANA (2017) .

context, remote sensing has been presented as a good option, especially for mapping irrigated areas (Ozdogan et al., 2010), as it presents advantages such as greater agility and lower cost compared to traditional methods such as in situ measures (Chen et al., 2018).

Normalized Difference Vegetation Index (NDVI) is the most utilized remote sensing based vegetation measure to agricultural monitoring, a widely used proxy for vegetation cover and production (Van Leeuwen et al., 2006). The strong relationship between NDVI and agricultural yield can be explored for monitoring changes in agricultural systems based on vegetation properties, such as length of the growing season, the onset date of greenness, and the date of maximum photosynthetic activity are often derived from NDVI time series. These phenological indicators emphasize different characteristics of terrestrial eco- 
systems to improve understanding of structure and function of land cover and associated changes such as response to natural or anthropogenic disturbances. In this context, the remote sensing based time series of NDVI are increasingly used to obtain phenological data at regional and global scales (Yin et al., 2012).

Enhanced Vegetation Index (EVI) is another important vegetation index used to improve sensitivity to high biomass regions and vegetation monitoring capability through a decoupling of the canopy background signal and a reduction in atmospheric influences. The EVI presents a more accurate vegetation response than NDVI due to reduced atmospheric effects and soil background response (Matsushita et al., 2007). Therefore, this index was used in this research to complement the information of phenological parameters derived from NDVI, to better characterize the crop fields, based on seasonal vegetation cycles.

Based on the aforementioned considerations, this paper proposes a novel approach to locating and quantifying center pivot irrigation systems based on objects detection using Circular Hough Transform (CHT) over a maximum vegetation response field (Greenest Pixel) and time series analysis of vegetation indices. The CHT is a simple feature extraction technique derived from the idea of parameter space, or Hough Space (HS), originally defined by the parametric representation used to describe lines in the picture plane using Hough Transform (HT) (Duda, Hart, 1972). This technique is widely used in digital image processing for detecting circles in low-quality images, because of its robustness in the presence of noise, occlusion, and varying illumination (Yuen et al., 1989. Dembele, 2015).

Furthermore, we implement Landsat data processing through a Javascript program using the Google Earth Engine's (GEE) application programming interface ${ }^{1}$ GEE is a freely accessible, cloud-based platform designed to enable remote sensing studies over long time scales and large spatial extents (Gorelick et al., 2017). This processing aiming to identify the maximum NDVI value, combining spatially overlapping images into a single image. The result is an image with the greatest photosynthetic activity at each pixel over the period (one year), which one improves the detection of circular crop fields made by center pivot systems. Especially when combined with analysis of vegetation indices time series (NDVI/EVI), to allow eliminate circles that do not show cyclical behavior of vegetative variability (planting/harvesting). The application programming interface of Web Time Series Service (WTSS) was used to acquire time series to do this task.

The goal of this works is to explore digital image processing methods to identify and quantify center pivot irrigation systems based on geometric shapes of these targets on remote sensing images to improve information about irrigation areas in the MATOPIBA region. Therefore, the main contribution consists of the combined use of image composition techniques to evidence the maximum vegetative response of irrigated fields and trend analysis of crop cycles through time series of vegetation indices to validate the results.

\section{MATERIAL AND METHODS}

\subsection{Study Area}

The MATOPIBA region considered the great national agricultural frontier today, is composed of four states, Maranhão, To-

\footnotetext{
${ }^{1}$ Data underlying the study are available at the Figshare repository, may be accessed at doi.org/10.6084/m9.figshare.c.4846911
}

cantins, Piauí and Bahia, both belonging to the Cerrado biome, and is responsible for much of the Brazilian grain production, with an area of about 73 million hectares (Embrapa, 2019). The delimitation of this region can be seen in Figure 2 where the region is represented by the red polygon.

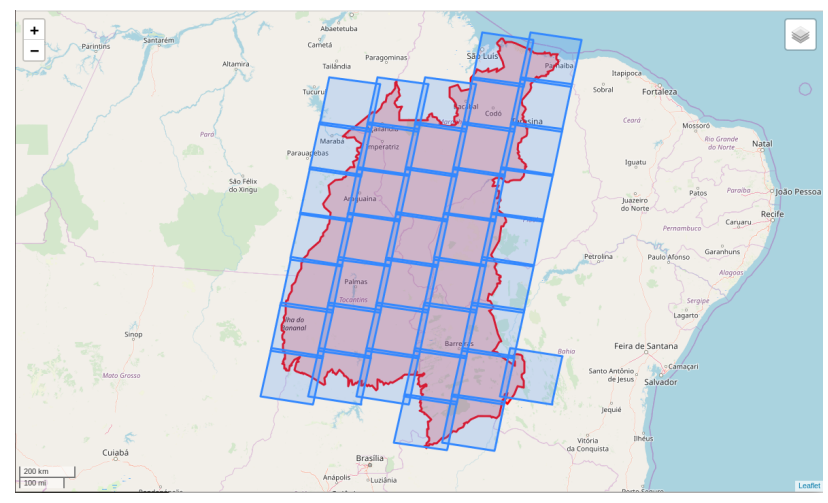

Figure 2. Map of study area overlaid by the Landsat 8 tiles $2^{2}$

\subsection{Data Sources Plataforms}

The detection of center pivots was developed using multi-source multi-temporal remote sensing data for the year 2017 and the geospatial vector dataset of center pivots mapped from $\mathrm{ANA}^{3}$ in collaboration with Brazilian Agricultural Research Corporation (Embrapa) for the same year, as the knowledge base. This mapping was performed through visual analysis of Landsat, Sentinel and other satellite images (ANA, Embrapa, 2019).

Data sources used for this work were time series of vegetation indices (NDVI/EVI) from MOD13Q1 product of sensor Moderate Resolution Imaging Spectroradiometer (MODIS) on AQUA/TERRA platforms, which has a 16 days temporal resolution and 250 meters spatial resolution (Didan, 2015). Another information used was the maximum response of vegetation, getting the pixel of major value from product NDVI estimated from bands of Operational Land Imager (OLI) on Landsat 8 (Roy et al., 2014) for period of study (a year).

Our approach used WTSS to obtain MODIS vegetation indices time series, this service is part of big project termed Web services for Big Earth Observation Data, this project from Brazil created a complete infrastructure with servers, open source libraries, and products to support research from various areas of Earth observation (Vinhas et al., 2017). Another source data used was scenes of Landsat 8 OLI acquired over MATOPIBA region for the year 2017, using the GEE platform, the coverage of the whole area of interest of this work requires 40 distinct tiles (Figure 2). The entire collection of images (835) was used because the main objective was to recover maximum vegetation response to improve border detection of crop fields. The clouds, shadows, and water bodies were masked using Quality Assessment (QA) bands included in Landsat Surface Reflectance Product. QA bands are important to identify the pixels

\footnotetext{
${ }^{2}$ The study area ranges in latitude from $-2.2193^{\circ}$ to $-15.2647^{\circ}$ and in longitude from $-41.7959^{\circ}$ to $-50.7421^{\circ}$. Geospatial data describing this area are available to download at http://mapas.cnpm.embrapa.br/ matopiba2015/

${ }^{3}$ GeoNetwork is the online repository of geospatial data made by ANA. Please refer to this address https: //metadados.ana.gov.br/geonetwork/srv/pt/main.home? uuid=e2d38e3f-5e62-41ad-87ab-990490841073 to take access of geospatial vector dataset of center pivots. Accessed in Jan. 22, 2020.
} 
that might be affected by instrument artifacts or subject to cloud contamination. This is necessary because NDVI calculated over pixels containing clouds will show lower values making it difficult to determine correct growing up of vegetation, would be taken an incorrect sense of vegetation reduction (USGS, 2019). These images (tiles) show the maximum NDVI per pixel over the analyzed period (a year). The number of pixels that contribute to the greenest-pixel composites varied by pixel and by tile, depending on the number of images available for each path/row or cloud cover frequency.

\subsection{Data Processing}

Our methodology described in Figure 3, show steps necessary to retrieve candidate circles of center pivot systems to compare with our knowledge database from ANA. Therefore, we used GEE to preprocess the Landsat collection scenes to compute of greenest pixel (maximum NDVI) composition, improving the delimitation of crop fields, and allowing identify possible circles of center pivots based in a parameter space defined of HT applied to circles, i.e., CHT.

The CHT proposed by Duda and Hart (1972) is one of the modified versions of the HT method to detect circular objects, being recognized as one of the most robust techniques for curve detection in noisy images (Rizon et al., 2005). This method aims to find circular patterns within an image based on peaks detection in 3D accumulator array representing parameter space $(a, b, r)$ defined by dimensions of image and range of radii (Duda, Hart, 1972). A set of feature points is mapped into image space to a set of accumulated votes (intersections) in parameter space ( $\mathrm{Ri}-$ zon et al., 2005). If a circle in the image is represented mathematically as:

$$
(x-a)^{2}+(y-b)^{2}=r^{2}
$$

where

$$
\begin{aligned}
& a, b=\text { coordinates of the circle center } \\
& r=\text { radius of circle } \\
& x, y=\text { image coordinates }
\end{aligned}
$$

Then an arbitrary edge point $(x, y)$ will be transformed into a circular cone in the $(a, b, r)$ parameter space. If all the image points lie on a circle then the cones will intersect at a single point in $(a, b, r)$ corresponding to the parameters of the circle (Yuen et al., 1989). This approach requires a very large number of points to be accumulated in three-dimensional parameter space to detect circles of various sizes in images, thereby imposing excessive requirements to storage and search (Davies, 1988).

In this sense, as a way to reduce these requirements, we used a more clever method of CHT implemented in the OpenCV Python library (2-1 Hough Transform - 21HT), which uses the gradient information of edges and decompose the circle finding problem into two stages. First, consisting of a 2D HT to find circle centers, considering that the center of a circle must lie along the gradient direction of each edge point on the circle, then the common intersection point of these gradients identifies the center of the circle. A two-dimensional array is required to accumulate the center finding transform, and candidate center parameters are identified by local peak detection. Second, based in 1D HT to determine radii, to identify the radius of circles, the distance of each point from a candidate center is calculated and a radius histogram is produced. The peaks in the radius histogram indicate evidence for circles (Yuen et al., 1989). Further details of 21HT method can be obtained at Yuen et al. (1990).

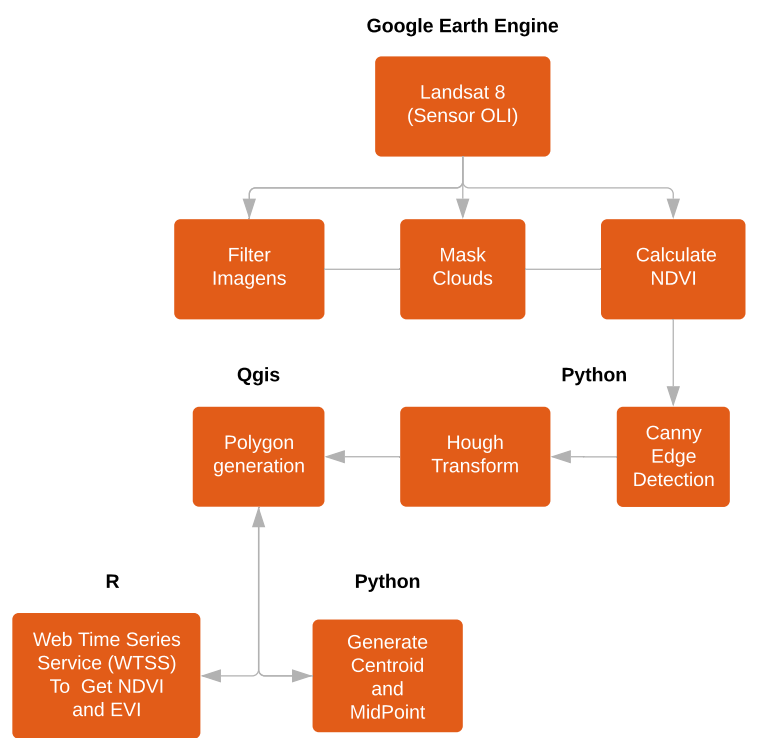

Figure 3. Flow chart of our approach.

In our workflow, we apply edge detection on greenest pixel images and use CHT implemented on OpenCV to retrieve candidate circles of center pivots. In this context, the 2D parameter space has the same scale of Landsat images, as described in Table 1 together with all the parameters used in 21HT method adjusted to our study area.

\begin{tabular}{|l|c|l|}
\hline Feature & Value & \multicolumn{1}{|c|}{ Meaning } \\
\hline $\mathrm{dp}$ & 1 & $\begin{array}{l}\text { Defines the size of accumulator } \\
\text { matrix relatively to your image } \\
\text { size. If dp=2, the accumulator has } \\
\text { half width and height, getting less } \\
\text { accurate circle parameters, but a } \\
\text { more strong voting }\end{array}$ \\
\hline param1 & 50 & $\begin{array}{l}\text { Gradient value used to handle edge } \\
\text { detection }\end{array}$ \\
\hline param2 & 15 & $\begin{array}{l}\text { It is the accumulator threshold for } \\
\text { the circle centers }\end{array}$ \\
\hline minDist & 34 & $\begin{array}{l}\text { Distance between the center of } \\
\text { circles detected }\end{array}$ \\
\hline minRadius & 10 & $\begin{array}{l}\text { Minimum size of the radius (in } \\
\text { pixels) }\end{array}$ \\
\hline maxRadius & 34 & $\begin{array}{l}\text { Maximum size of the radius (in } \\
\text { pixels) }\end{array}$ \\
\hline
\end{tabular}

Table 1. Parameters adjusted to $\mathrm{CHT}^{4}$

\subsection{Data Analysis}

The data analysis was carried out using $\mathrm{R}$ and Python programming languages due to the facilities provided by their libraries and packages. For instance, the GeoPandas library was used to generate points (centroid and midpoints) into objects identified in images through CHT (GeoPandas Development Team, 2019).

For each circle retrieved from HS corresponding to the response of a possible center pivot circle, the algorithm used the WTSS

\footnotetext{
${ }^{4}$ Additional information about the parameters used in function cv2.HoughCircles, available on OpenCV docs at https://docs.opencv.org/2.4.13.7. Accessed on Feb. 5, 2020.
} 
to recover time series of vegetation indices (NDVI/EVI) in order to characterize the phenological behavior of the surrounding region. It is worth mentioning that four cardinal directions midpoints used to extract the time series of each circle retrieved, aiming at the characterization of partial circles of center pivots.

The period analyzed to validate the center pivots detection was November 2017 to March 2018, corresponding to the crop season in the region of study. Because the vegetation index would be higher at this time, compared to the rest of the year. As the targets of this work are objects with cycles of growing vegetation, a time series analysis based on phenological parameters, such as amplitude and standard deviation of NDVI/EVI curves corresponding to seasonal vegetation cycles, was performed to remove some circles that were detected, but are not really crop fields. For this, we used the standard deviation, because the vegetation indices at the time the crop is in development are quite different when the crop is harvested.

The thresholds $\left(N D V I_{\text {amplitude }}=0.06, N D V I_{\text {std }}=0.02\right.$, $E V I_{\text {amplitude }}=0.07$ and $\left.E V I_{\text {std }}=0.02\right)$ used for circles exclusion, were based on the values extracted from time series of all center pivots mapped by ANA in the MATOPIBA region. These times series was acquired from the midpoint between the centroid and the main cardinal directions (4 points) of each circle defined in spatial vector file from ANA, to enable trend analysis through the mean value of the standard deviation and amplitude from vegetation indices. First, we eliminated the circles that had series lower than the standard deviation of reference (ANA), with this approach, the number of circles that did not correspond to pivots decreased significantly. After this stage, the circles that presented amplitude smaller than the ANA points were also removed.

\section{RESULTS}

Figure 4 shows two points representing the centroids of candidate circles detected by the CHT, one really represents a center pivot, while the other represents a point located on a dune region in Maranhão. With WTSS it is possible to analyze the vegetation index of each location. As depicted in Figure 5, the time series for both locations are quite different. The series of point (a) presents the cycle characteristic, with ups and downs, whereas the series of point (b) practically does not vary and is very close to 0 in the analyzed period. The identification of a false circle (pivot) here occurs because the region shown in (b) is located at Lençóis Maranhenses National Park that is composed of rolling sand dunes. During the rainy season, it's valleys are filled with freshwater forming numerous lagoons (blue contours), which cause radiometric saturation at sensor OLI of Landsat 8 (missing data) generating many edges. This is because highly reflective surfaces and sun glint over water bodies is an important factor that could cause the saturation of the reflective wavebands (Roy et al., 2016 Zhou et al., 2017).

The analysis of the time series allows eliminating most cases of false detection based on the trend of agricultural cycles. There remains a limitation regarding the shape of the crop fields found, for example, the Figure 6 highlights a cluster of center pivots correctly identified after object detection process (CHT) and filtering using vegetation index time series because they met the permanence criteria (thresholds). On the other hand the Figure 7 shows traditional fields of agriculture, rectangular, these fields remain even with the application of the filters, as they are also cultivated areas, they fall within the established vegetation

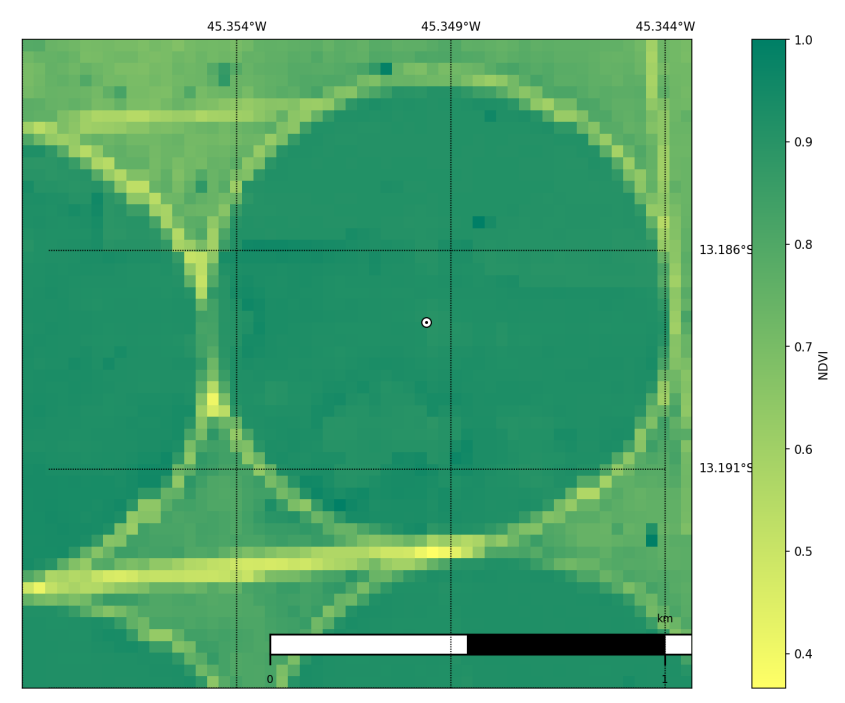

(a) Pivot

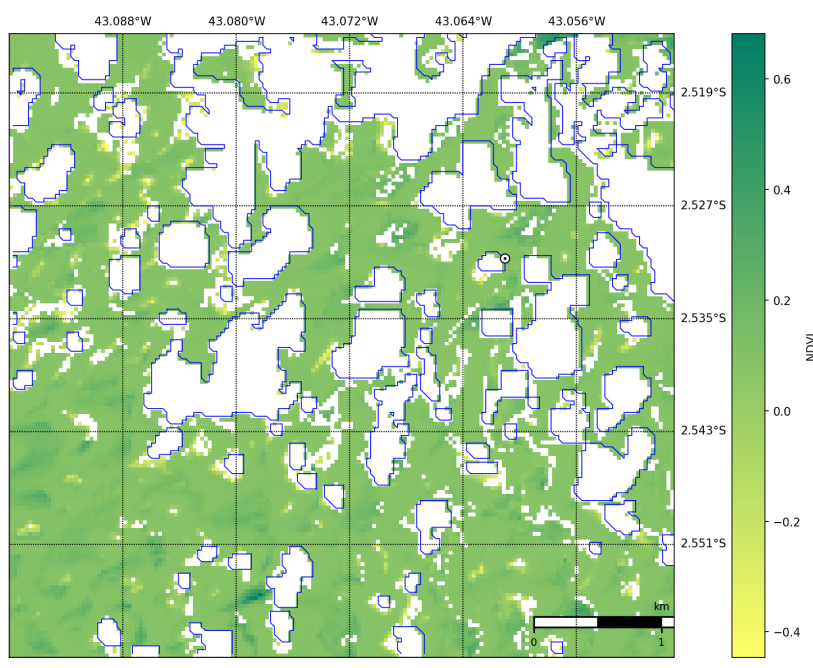

(b) Not Pivot

Figure 4. The centroids of candidate circles detected with CHT.

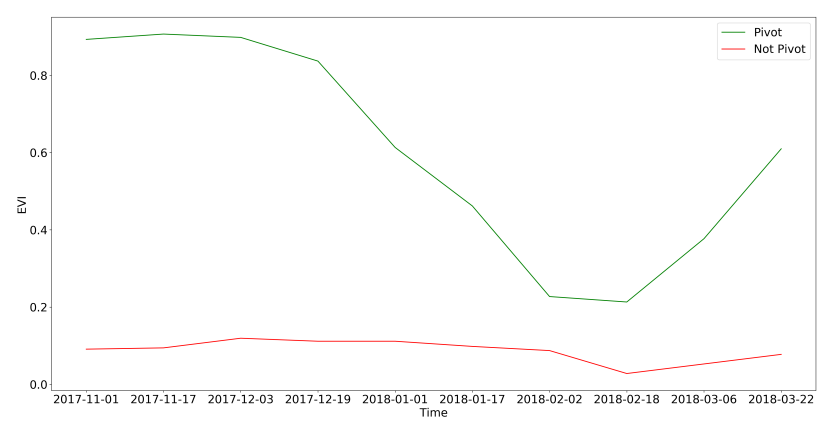

Figure 5. Example of time series.

thresholds. The overall potential of the result of our approach is showed spatially in Figure 8 the percentage was calculated considering existence or not of center pivots in each tile covering the MATOPIBA region. 


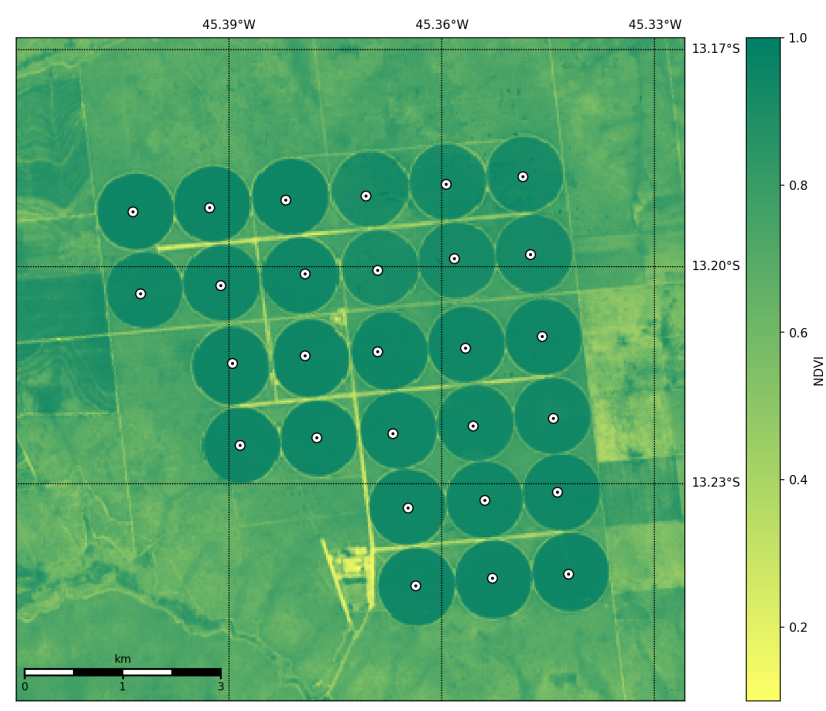

Figure 6. Center pivots detected.

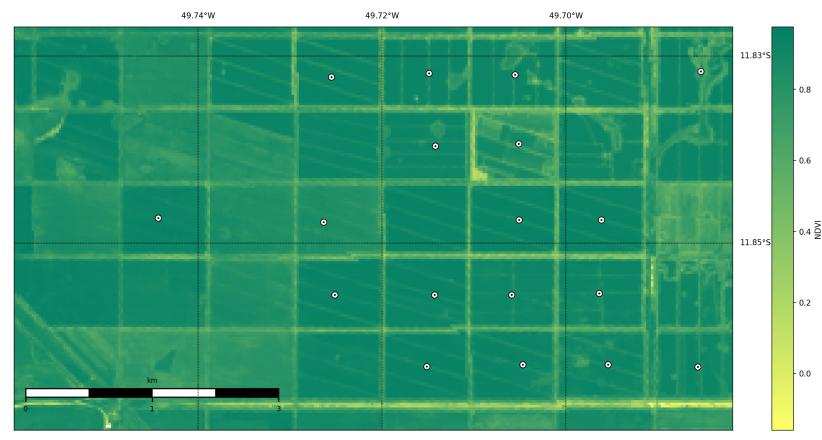

Figure 7. Agricultural field detected.

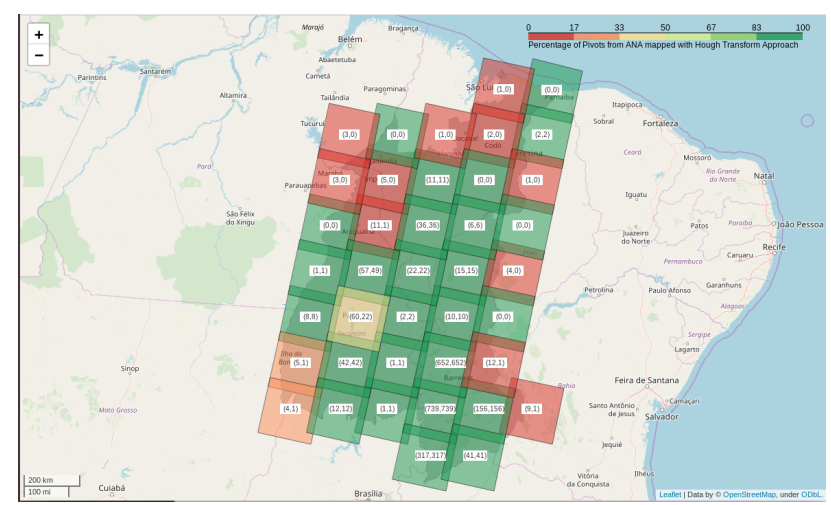

Figure 8. Potencial of pivots recovery using CHT.

\section{DISCUSSION}

Our approach detected about $80 \%(1424 / 1762)$ of the center pivots mapped by ANA in the MATOPIBA region. Considering the percentage per state, Piauí and Bahia showed better detection results with values of $90 \%(18 / 20)$ and $85 \%(1302 / 1517)$ respectively, while Maranhão obtained 57\% (40/69) and Tocantins $41 \%(64 / 156)$ (Figure 9). The accuracy for the last two states was affected by the aforementioned problems, such as sun glint over water bodies and crop field format.

The time series analysis supported by WTSS showed good performance regarding the elimination of non-pivot irrigation sys- tems. However, this approach has a limitation when the object retrieved is a cultivation field not necessarily irrigated by the center pivot. A possible solution for this issue would be to add an extra step to analyze the shape of the object retrieved using edge information.

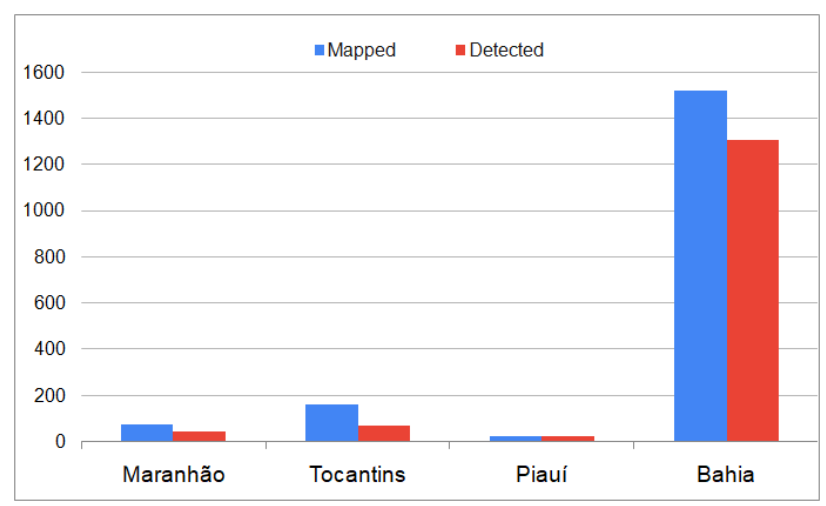

Figure 9. Center pivots mapped by ANA vs detected by our method.

\section{CONCLUSIONS}

The analysis of circles detected in the images of the MATOPIBA region using time series is an effective automatic method for detecting central pivot irrigation systems. The results obtained were very similar to those mapped by ANA through the costly approach of visual analysis.

From the analyzed areas it was found that several factors can influence the detection, such as the frequency of clouds and shadows, sun glint, and so on. These factors contribute to the generation of false-positive cases impacting the accuracy of the method in addition to increasing the computational cost of the analysis made based on time series. This shows the need for a broad understanding of the agricultural dynamics of the studied region, besides the use of robust techniques to analyze land use processes.

As future work, we plan to use other methods to adjust thresholds and refine the filter process, for example, the Time-Weighted Dynamic Time Warping (TWDTW) method allows identifying patterns of vegetation dynamics from MODIS EVI data to classify land use and land cover types (Maus et al., 2016). Using this information can improve the identification of crop field objects retrieved from HS, through the mining of time series. In addition, we plan to improve the automatic detection of center pivots using Machine Learning, especially convolutional neural networks, due to its capacity to classify targets based on features characteristics in their layers.

\section{ACKNOWLEDGEMENTS}

This work was partially supported by São Paulo Research Foundation (FAPESP) grant 2017/24086-2, grant 2018/16221-0 and the Coordination for the Improvement of Higher Education Personnel (CAPES) code 001. Also we thank National Institute for Space Research for the research support. 


\section{REFERENCES}

ANA, 2017. Atlas irrigação: Uso da água na agricultura irrigada. Technical report, National Water Agency (ANA). arquivos.ana.gov.br/imprensa/publicacoes (10 May 2019).

ANA, Embrapa, 2019. Levantamento da agricultura irrigada por pivôs centrais no Brasil (1985-2017). Technical report, National Water Agency (ANA) and Brazilian Agricultural Research Corporation (Embrapa) Maize/Sorghum. ana.gov.br (10 May 2019).

Bastiaanssen, W. G., Molden, D. J., Makin, I. W., 2000. Remote sensing for irrigated agriculture: Examples from research and possible applications. Agricultural Water Management, 46(2), 137-155. doi.org/10.1016/S0378-3774(00)00080-9.

Chen, Y., Lu, D., Luo, L., Pokhrel, Y., Deb, K. Huang, J., Ran, Y., 2018. Detecting irrigation extent, frequency, and timing in a heterogeneous arid agricultural region using MODIS time series, Landsat imagery, and ancillary data. Remote Sensing of Environment, 204, 197-211. doi.org/10.1016/j.rse.2017.10.030.

Davies, E. R., 1988. A modified Hough scheme for general circle location. Pattern Recognition Letters, 7(1), 37-43. doi.org/10.1016/0167-8655(88)90042-6.

Dembele, F., 2015. Object detection using Circular Hough Transform. Université Laval. wcours.gel.ulaval.ca/2015/a/GIF7002/default/5notes [Lectures supplémentaires C11:d] (25 January 2019).

Didan, K., 2015. MOD13Q1 MODIS/Terra vegetation indices 16-day 13 global $250 \mathrm{~m}$ sin grid v006 [data set]. NASA EOSDIS Land Processes DAAC. doi.org/10.5067/MODIS/MOD13Q1.006 (27 August 2019).

Duda, R. O., Hart, P. E., 1972. Use of the Hough transformation to detect lines and curves in pictures. Communications of the ACM, 15(1). doi.org/10.1145/361237.361242.

Embrapa, 2019. Matopiba. Brazilian Agricultural Research Corporation (Embrapa). embrapa.br (26 August 2019).

GeoPandas Development Team, 2019. GeoPandas Library, Version 0.5.1. GeoPandas developers Revision 4a4ede8b. geopandas.readthedocs.io/en/v0.5.1 (27 August 2019).

Gorelick, N., Hancher, M., Dixon, M., Ilyushchenko, S., Thau, D., Moore, R., 2017. Google Earth Engine: Planetary-scale geospatial analysis for everyone. Remote Sensing of Environment. doi.org/10.1016/j.rse.2017.06.031.

MAPA, 2017. Projeções do agronegócio : Brasil 2016/2017 a 2026/2027 Projeções de Longo Prazo. Technical report (Version of 15 August 2017), Ministry of Agriculture, Livestock and Food Supply (MAPA). agricultura.gov.br (1 September 2019).

Matsushita, B., Yang, W., Chen, J., Onda, Y., Qiu, G., 2007. Sensitivity of the Enhanced Vegetation Index (EVI) and Normalized Difference Vegetation Index (NDVI) to Topographic Effects: A Case Study in High-density Cypress Forest. Sensors, 7(11), 2636-2651. doi.org/10.3390/s7112636.

Maus, V., Câmara, G., Cartaxo, R., Sanchez, A., Ramos, F. M., de Queiroz, G. R., 2016. A Time-Weighted Dynamic Time Warping Method for Land-Use and LandCover Mapping. IEEE Journal of Selected Topics in Applied
Earth Observations and Remote Sensing, 9(8), 3729-3739. doi.org/10.1109/JSTARS.2016.2517118.

Ozdogan, M., Yang, Y., Allez, G., Cervantes, C., 2010. Remote Sensing of Irrigated Agriculture: Opportunities and Challenges. Remote Sensing, 2(9), 2274-2304. doi.org/10.3390/rs2092274.

Rizon, M., Yazid, H., Saad, P., Md Shakaff, A. Y., Saad, A. R., Sugisaka, M., Yaacob, S., Mamat, M., Karthigaya, M., 2005. Object Detection using Circular Hough Transform. American Journal of Applied Sciences, 2(12), 1606-1609. doi.org/10.3844/ajassp.2005.1606.1609.

Roy, D., Kovalskyy, V., Zhang, H., Vermote, E., Yan, L., Kumar, S., Egorov, A., 2016. Characterization of Landsat-7 to Landsat-8 reflective wavelength and normalized difference vegetation index continuity. Remote Sensing of Environment, 185, 57-70. doi.org/10.1016/j.rse.2015.12.024.

Roy, D., Wulder, M., Loveland, T., C.E., W., Allen, R., Anderson, M., Helder, D., Irons, J., Johnson, D., Kennedy, R., Scambos, T., Schaaf, C., Schott, J., Sheng, Y., Vermote, E., Belward, A., Bindschadler, R., Cohen, W., Gao, F., Hipple, J., Hostert, P., Huntington, J., Justice, C., Kilic, A., Kovalskyy, V., Lee, Z., Lymburner, L., Masek, J., McCorkel, J., Shuai, Y., Trezza, R., Vogelmann, J., Wynne, R., Zhu, Z., 2014. Landsat-8: Science and product vision for terrestrial global change research. Remote Sensing of Environment, 145, 154 172. doi.org/10.1016/j.rse.2014.02.001.

USGS, 2019. Landsat Surface Reflectance Quality Assessment. U.S. Geological Survey (USGS). usgs.gov (27 August 2019).

Van Leeuwen, W. J., Orr, B. J., Marsh, S. E., Herrmann, S. M., 2006. Multi-sensor NDVI data continuity: Uncertainties and implications for vegetation monitoring applications. Remote Sensing of Environment, 100(1), 67-81. doi.org/10.1016/j.rse.2005.10.002.

Vinhas, L., de Queiroz, G. R., Ferreira, K. R., Camara, G., 2017. WEB SERVICES FOR BIG EARTH OBSERVATION DATA. Revista Brasileira de Cartografia, 69(5). www.seer.ufu.br/index.php/revistabrasileiracartografia.

Yin, H., Udelhoven, T., Fensholt, R., Pflugmacher, D., Hostert, P., 2012. How Normalized Difference Vegetation Index (NDVI) Trends from Advanced Very High Resolution Radiometer (AVHRR) and Système Probatoire d'Observation de la Terre VEGETATION (SPOT VGT) Time Series Differ in Agricultural Areas: An Inner Mongolian Case Study. Remote Sensing, 4(11), 3364-3389. doi.org/10.3390/rs4113364.

Yuen, H. K., Princen, J., Illingworth, J., Kittler, J., 1989. A comparative study of hough transform methods for circle finding. Proc. 5th Alvey Vision Conf., Reading (31 Aug, 169-174.

Yuen, H., Princen, J., Illingworth, J., Kittler, J., 1990. Comparative study of Hough Transform methods for circle finding. Image and Vision Computing, 8(1), 71-77. doi.org/10.1016/02628856(90)90059-E.

Zhou, Y., Dong, J., Xiao, X., Xiao, T., Yang, Z., Zhao, G., Zou, Z., Qin, Y., 2017. Open surface water mapping algorithms: A comparison of water-related spectral indices and sensors. Water (Switzerland), 9(4). doi.org/10.3390/w9040256. 